\title{
ROLE OF VETERINARIAN IN ANIMAL WELFARE ISSUE: A GLOBAL CONCEPT
}

\author{
M. Ariful Islam \\ Department of Medicine, Faculty of Veterinary Science \\ Bangladesh Agricultural University, Mymensingh-2202, Bangladesh
}

\begin{abstract}
ANIMAL WELFARE
Animal welfare is the well-being of animals. The standards of "good" animal welfare vary considerably between different contexts. These standards are under constant review and are debated, created and revised by animal welfare groups, legislators and academics worldwide (Hewson, 2003). It is strongly linked to animal health, which similarly depends on good animal husbandry. Animal welfare is a core mandate of the veterinary community generally and veterinarians individually. This concept is articulated by many veterinary organizations in their Code of Practice, Veterinary Oath or other statements of commitment. Such statements centre on the common theme "a veterinarian should be dedicated to the benefit of society, the conservation of animal resources and the relief of suffering of animals and to promote animal wellbeing". As scientific knowledge in the field of animal welfare expands and the expectations of society change in regard to animal care, so the commonly accepted definitions of animal welfare have evolved. Knowledge of animal welfare, particularly those in production is becoming essential to veterinary professionals across the globe.

In 2008 the World Reference Organization for Animal health (OIE) adopted a definition on animal welfare: "Animal welfare means how an animal is coping with the conditions in which it lives. An animal is in a good state of welfare if (as indicated by scientific evidence) it is healthy, comfortable, well nourished, safe, able to express innate behaviour, and if it is not suffering from unpleasant states such as pain, fear and distress. Good animal welfare requires disease prevention and veterinary treatment, appropriate shelter, management, nutrition, humane handling and humane slaughter/killing. Animal welfare refers to the state of the animal; the treatment that an animal receives is covered by other terms such as animal care, animal husbandry and humane treatment". This definition clearly shows that an animal can experience both good and poor welfare and that there are important factors that influence its welfare. This definition is reflective of the "Five Welfare Freedoms" that are widely accepted as the foundation of good animal welfare and which are supported by the World Veterinary Association (Vallat, 2008).

The concept of "Freedom Five" is summarized as:

1. Freedom from thirst, hunger and malnutrition- by ready access to fresh water and a diet to maintain full health and vigour;

2. Freedom from discomfort- by providing a suitable environment including shelter and a comfortable resting area;

3. Freedom from pain, injury and disease- by prevention or rapid diagnoses and treatment;

4. Freedom to express normal behaviour- by ensuring conditions that avoid mental sufferings; and by providing sufficient space, proper facilities, and company of the animal's own kind; and

5. Freedom from fear and distress- by ensuring conditions that avoid mental sufferings.
\end{abstract}

\section{VETERINARIAN'S ROLE}

Members of the veterinary profession have a wide range of expertise and skills that make veterinarians unique in their understanding of animal behaviour and animal welfare. Veterinarians have the pragmatism to examine and assess the welfare of animals in their environment and to make recommendations to improve welfare where that is required. Traditionally, the veterinary community has engaged in providing the means to accomplish good animal welfare. These activities encourage: disease prevention and veterinary medical treatment, provision of appropriate shelter, good management, proper nutrition, humane handling, humane transportation and humane killing (Edwards and Schneider, 2005).

*Corresponding e-mail address: maislam77@bau.edu.bd

Copyright (c) 2015 Bangladesh Society for Veterinary Medicine

All rights reserved 0318/2015 


\section{Ariful Islam}

Veterinarians play a key role in the tripartite association formed by animals, animal owners and society but it could be differ from region to region. This role shall be science basedobjective, having independent and impartial modality. Veterinarians shall be licensed and supervised by the independent Veterinary Statutory Body of the country. Though the veterinary profession is committed to promote animal welfare through the state of art and science of keeping animals fit through attention to good husbandry, hygiene, preventive medicine and prompt treatment of injury and diseases, it lacks in its attention to the study of how the animal feels.

Veterinary engagement in animal welfare must encompass a wide range of activities, including, but not limited to (OIE, 2008):

1. Veterinarian daily practices.

2. Veterinary advocacy to animal owners.

3. Education and promotion of animal welfare to the wide public.

4. Animal welfare scientific research.

5. Drafting animal welfare legislations and participating in programs and projects.

6. Collaboration with other interested parties on animal welfare.

\section{Veterinarian daily practices}

This is considered a professional obligation for any member of the veterinary community. In their everyday dealing with animals, veterinarians must always adhere to the principals of care and compassion which can be expressed by providing appropriate veterinary medical care and disease prevention, development and applying effective management protocols and techniques and sufficient and qualified staff to ensure routine veterinary activities to be performed with less duress to the animals and in an animal compassionate manner.

\section{Veterinary advocacy to animal owners}

Veterinarians have the scientific and medical training as well as the statutory accountability to ensure animal welfare expectations and standards are met. Veterinarians are best positioned in the light of knowledge and skills about animal management and to motivate their owners.Licensed Veterinarian can teachanimal owners, managers and other members of the community to protect and improve welfare of animals. In addition to specific training, they must foster and promote best animal management practices and the understanding of the benefits from such practices.

\section{Education and promotion of animal welfare to the wide public}

Veterinarians shall become sufficiently influential and act as the society animal welfare main source to give science-based expertise and educate the wide public on basic animal husbandry. There is increased interest and concern from the wide public on how animals are used and treated. Peoples those live in the city have no understand of basic animal husbandry and their pet or companion animal husbandry and health management.

\section{Animal welfare scientific research}

Animal welfare is a multidisciplinary field of expertise which includes veterinary science, ethics, religions, politics, economics etc. It is evident that further scientific research in these areas is necessary in order to understand better and to discover best practices to enhance animal welfare. Veterinarian could perform such animal welfare through research as they have the scientific and medical training as well as the statutory accountability to work in research areas and to collaborate with scientific and other experts in a variety of capacities in the animal welfare field.

\section{Taking part in drafting animal welfare legislationsand in animal welfare programs}

All legislation related to animal welfare should be drafted in close co-operation with veterinarians and veterinary associations. As the need for animal welfare voluntary and regulatory acts and assurance programs increases, there is a role for veterinarians to play in both their development and implementation. Veterinarians need to assure that the Animal Welfare Acts and programs are useful and truly serve societal need as well as the needs of the animals. 


\section{Collaboration with other interested parties}

Veterinarians should make themselves available to cooperate with all interested parties (e.g. legislators, livestock and food industries, animal welfare organization, consumer organization. etc.) to improve the welfare and well-being of animals. There are numerous animal welfare programs, projects, initiatives on different national and international levels involving government and private sector to improve and promote the welfare and the protection of animals in different fields.

In summary, the veterinary profession is the well prepared and responsible to use its skills and expertise to help animal owners, managers and the public to provide the best practices and education about animal welfare. This profession has great potential, opportunity and responsibility to engage in a wide range of employment fields that deliver animal welfare services to the benefit of society and all animals. Veterinarians should continue to identify current needs and future developments and to ensure that veterinarians are always properly trained in the field of animal welfare. Veterinarians have the necessary skills and tools to meet the social expectations and profession obligations regarding to animal welfare.In addition, Veterinarians should make themselves available to cooperate with all interested parties to improve the welfare and well-being of animals. All legislation related to animal welfare should be drafted in close co-operation with veterinarians and veterinary associations.

Above all, in countries where there is no animal welfare Acts, the National Veterinary Associations or councils should initiate such legislation.

\section{REFERENCES}

1. Hewson CJ (2003). "What is animal welfare? Common definitions and their practical consequences". The Canadian Veterinary Journal 44: 496-499.

2. Jan Ladewig (2008). The role of the veterinarian in animal welfare. Acta Veterinaria Scandinavica 50(Suppl 1): S5 (19 August 2008).

3. Edwards JD and Schneider HP (2005). The World Veterinary Association and animal welfare. Revue scientifique et technique (International Office of Epizootics) 24: 639-646.

4. Kenneth L Easton (2004). The veterinarian's role in animal welfare. Canadian Veterinary Journal 45: 1030.

5. OIE (2008). http://www.oie.int/doc/ged/D7201.pdf

6. Vallat Bernard (2008). Guide to animal welfare in dairy production. International Dairy Foundation, OIE. 